Check for updates

Cite this: RSC Adv., 2019, 9, 17856

Received 4th April 2019

Accepted 28th May 2019

DOI: 10.1039/c9ra02556a

rsc.li/rsc-advances

\section{Electrochemical monitoring of ROS influence on seedlings and germination response to salinity stress of three species of the tribe Inuleae $\uparrow$}

\author{
Antonio Doménech-Carbó, (DD *a Paula Cervelló-Bulls, ${ }^{a}$ José Miguel González, ${ }^{a}$ \\ Pilar Soriano, ${ }^{b}$ Elena Estrelles ${ }^{\mathrm{b}}$ and Noemí Montoya ${ }^{a}$
}

\begin{abstract}
Solid-state electrochemical methods have been applied to the establishment of patterns of plant growth and response to saline stress using seedlings of Inula helenium L., Dittrichia viscosa (L.) Greuter (Inula viscosa (L.) Aiton), Limbarda crithmoides (L.) Dumort (Inula crithmoides L.). Upon in situ electrochemical generation of reactive oxygen species (ROS) the reactivity with such species was monitored using voltammetric signals associated to the oxidation of polyphenolic components of the plants. A simple kinetic model based on second-order reaction between ROS and polyphenolic components is applied to electrochemical data yielding apparent rate constants which can be correlated with the level of saline stress revealing significant differences between the tested species. These results were contrasted with the seed germination response to salt concentration in order to check potentiality of voltammetric techniques as analytical tools for evaluating salt stress tolerance in plants.
\end{abstract}

\section{Introduction}

Soil salinity is one of the most important abiotic stresses in plants determining success in germination and seedling establishment. This factor induces alterations in the plant life cycle as a consequence of the effect on physiological and biochemical attributes, ${ }^{1}$ and usually acts as a limiting factor that determines the distribution of species in salt marshes and other habitats where salt is present.

Salt tolerance in plants is a result of the interaction of several factors that cover different aspects of plant physiology. These aspects are linked to ion compartmentalization, osmolyte production, osmotic adjustment, selective transport and uptake of ions, enzymatic and nonenzymatic antioxidant response to maintain the balance of reactive oxygen species (ROS), salt inclusion/excretion, and regulation of the expression levels of different genes associated to salt tolerance. ${ }^{2-5}$ To reduce the harmful effects of salt, plants use a series of morphological, physiological and biochemical adaptations related to escape, avoidance and tolerance mechanisms. ${ }^{6}$

ROS play an important role in several biological processes occurring in plants. ${ }^{7}$ Apart from hydroxyl radicals $\left(\mathrm{HO}^{\circ}\right)$, superoxide radical anion $\left(\mathrm{O}^{\cdot-}\right)$, hydroperoxide radical $\left(\mathrm{HO}_{2}{ }^{\circ}\right)$,

${ }^{a}$ Department of Analytical Chemistry, University of Valencia, Dr Moliner, 50, Burjassot, 46100,Valencia, Spain.E-mail: antonio.domenech@uv.es

${ }^{b} I C B i B E-B o t a n i c$ Garden of the University of Valencia, Quart, 80, 46008, Valencia, Spain

$\dagger$ Electronic supplementary information (ESI) available. See DOI: $10.1039 / \mathrm{c} 9 \mathrm{ra02556a}$ and hydrogen peroxide $\left(\mathrm{H}_{2} \mathrm{O}_{2}\right)$ can participate in a number of biochemical processes and, in particular, in adaptions associated to both abiotic and biotic stress. ${ }^{8}$

ROS are involved in signaling events in normal cellular metabolism and are produced from a variety of cytosolic enzyme systems. However, at high concentrations, they produce toxic effects leading to the so-called "oxidative stress", a condition that disrupts redox signaling and control..$^{9,10}$ Accordingly, plant cells have to be at least two mechanisms of ROS removing, the first one controlling the fine modulation of their concentration for signaling purposes, and the second to eliminate high concentration levels of ROS in particular associated to the occurrence of hydric, saline, etc. stress. ${ }^{11-13}$

Due to the connection of oxidative stress with DNA mutagenesis $^{14}$ and different diseases, ${ }^{15-17}$ there is an increasingly growing interest in evaluating the antioxidant effect of chemicals, foods, vegetal extracts, etc. ${ }^{18}$ Although a variety of methods have been proposed for this purpose, most of them are based on chemical reactions with producers/scavengers of radicals (typically, 2,2-diphenyl-2-picrylhydrazyl (DPPH'), fluorescein-AAPH (2,2'-azobis-2-methylpropanimidamide dihydrochloride)), and monitoring Fenton-reaction, using 1,10-phenanthroline, ${ }^{18,19}$ these assays, including several electrochemical ones, ${ }^{20,21}$ measure a 'global', long time antioxidant activity of plant extracts (or individual plant components when these are isolated) but, as well as conventional HPLC studies, ${ }^{11-13,18,19}$ do not provide direct mechanistic information on ROS reactivity with the components of vegetal matter.

In this context, we have developed a solid-state electrochemical methodology for studying the interaction between 
vegetal matter and electrochemically generated ROS aimed to monitor the reactivity of polyphenolic components of fruits ${ }^{22}$ and possible ROS relation with gynodioecy. ${ }^{23}$ This methodology exploits the possibility of electrochemical generation of ROS by applying reductive potential inputs to air-saturated aqueous solutions, ${ }^{24-26}$ combined with the voltammetry of immobilized particles (VIMP), a solid state technique developed by Scholz et $a l^{27,28}$ which provides analytical information on sparingly soluble solids attached to inert electrodes in contact with suitable electrolytes. ${ }^{29}$ The VIMP was previously applied to determine antioxidant capabilities of vegetal products ${ }^{30,31}$ and for electro-chemotaxonomic purposes ${ }^{32,33}$ and monitoring plant defense against external stressors. ${ }^{34}$

The current work reports the application of this methodology to monitor the interaction of ROS with the components of extracts from seedlings of Inula helenium L., Dittrichia viscosa (L.) Greuter, and Limbarda crithmoides (L.) Dumort, three species of the tribe Inuleae. This is a large tribe, belonging the Asteraceae family, that comprises more than 50 genera whose species are widespread in temperate regions of Europe, Asia and North of Africa. Its genera are a good example of habitat diversity so that the salt tolerance varies between species, even of the same genus, according to the ecological characteristics of their habitat.

The voltammetric method exploits the electroactive character of polyphenolic compounds, (lignins, flavonoids, flavonols, flavones, ....) abundantly represented in the leaves of the tribe. ${ }^{35-40}$ Most of these components display well-known oxidations of $o$-catechol units to the corresponding $o$ quinones highly sensitive to the overall molecular structure..$^{20-23,30-34,41,42}$ Ultimately, the current work was aimed to provide an analytical tool to be used in the botanic science frame to acquire 'direct' mechanistic information on ROS reactivity and its relation with biochemical processes that is unavailable from the usual HPLC methodologies. As an illustrative example, here we compare the salt tolerance of the previously mentioned species in germination phase. The use of the proposed electrochemical methodology, although does not provide a so detailed knowledge of the composition of vegetal matter as HPLC-MS, offers three potential advantages: (i) the representativity of the vegetal samples, as far as no prolonged pretreatments are required; (ii) the possibility of in situ generation of ROS; (iii) the relative simplicity of the voltammetric response (only a limited number of chemical components are electroactive), which facilitates its use for quantitative purposes. This is of interest because relatively few quantitative studies have been reported on the kinetic of plant growth and metabolism, ${ }^{\mathbf{9}}$ ethylene production, ${ }^{\mathbf{4 3}}$ effect of temperature, $\mathrm{pH}$ and salt stress on seed germination. ${ }^{\mathbf{4 4}}$

To describe the kinetics of the interaction of electroactive plant components with ROS and quantify the influence on it of saline stress a simplified theoretical model is presented. Testing the theoretical model, whose scope and limitations will be also discussed, with electrochemical data was based on voltammetric measurements at microparticulate deposits from ethanolic extracts of leaves of seedlings of the aforementioned species.

\section{Experimental}

\section{Selection of the studied taxa}

The research was carried out using three different species of the genera Inula, Dittrichia and Limbarda. These species were previously included in the same genus, Inula, of the family Asteraceae (=Compositae): Inula helenium L., Dittrichia viscosa (L.) Greuter, (Inula viscosa (L.) Aiton), and Limbarda crithmoides (L.) Dumort, (Inula crithmoides L.). However, currently they are considered three different genera within the tribe Inuleae, belonging to the family Asteroidae. ${ }^{45}$ The selection took into account the taxonomic proximity between genera and their distribution in different type of habitats, subjected to very different salt stress levels.

Dittrichia viscosa is a species widespread throughout the Mediterranean areas, generally living in altered and anthropized areas like abandoned crop fields, debris storage areas or altered road edges. ${ }^{46}$ Limbarda crithmoides is a succulent perennial species distributed in Western Europe, and Mediterranean basin, mainly in coastal areas, living in salt marshes, halophilous reedbeds, coastal sands, shingle banks and maritime cliffs. ${ }^{47}$ Inula helenium is a perennial species, it is widely distributed in Europe, East Asia and North America, ${ }^{47}$ growing in woodland margins, roadsides, meadows, usually close to cultivated fields and inhabited areas. It is a widely cultivated species by its high ornamental value.

\section{Germination experiments}

To check seed germination tolerance to salt, seeds were sowed on increasing salt concentrations: 50, 100, 150, 200, 300, and $400 \mathrm{mM}$ of $\mathrm{NaCl}$, in order to compare the response to a control without salt in the medium. The substrate with the different salt solutions was prepared with agar $0.6 \%$, and germination was conducted at $25{ }^{\circ} \mathrm{C}$, temperature previously established as optimal, with a $12 / 12 \mathrm{~h}$ photoperiod $\left(100 \mu \mathrm{mol} \mathrm{m}{ }^{-2} \mathrm{~s}^{-1}\right)$ with fluorescent daylight tubes, during 30 days. After this testing period, no germinated seeds in the plates with salt concentration from $100 \mathrm{mM}$ were transferred to $0.6 \%$ agar substrate without any salt traces, to check the germination recovery capacity of seeds after salt exposition. The germination recovery experiments were maintained one additional week. Germination results in the different conditions were expressed as the mean and standard deviation. The differences in the observed response in salt tests respect to the control were statistically compared respect to the control through a Dunnett test.

\section{Electrochemical measurements}

Electrochemical experiments were performed at $298 \pm 1 \mathrm{~K}$ in a three-electrode using a $\mathrm{CH}$ I660 potentiostat (Cambria Scientific, Llwynhendy, Llanelli UK). The three-electrode arrangement was formed by BAS (Bioanalytical Systems, West Lafayette, USA) MF2012 glassy carbon working electrode (GCE) (geometrical area $0.071 \mathrm{~cm}^{2}$ ), a platinum wire auxiliary electrode, and an $\mathrm{Ag} / \mathrm{AgCl}(3 \mathrm{M} \mathrm{NaCl})$ reference electrode. To ensure repeatability, a voltammogram on the bare electrode after mechanical cleaning in a polishing clot with alumina slurry was 
performed before each voltammogram at sample-modified electrode. For electrode modification, the glassy carbon surface was coated with a microparticulate deposit of organic compounds resulting from the evaporation at air of an aliquot of $50 \mu \mathrm{L}$ of the suspension resulting from the maceration during $1 \mathrm{~min}$ of a leaf fragment (ca. $200 \mathrm{mg})$ in ethanol $(2 \mathrm{~mL})$ with an agate mortar and pestle. The aliquot of ethanolic suspension was immediately transferred onto the electrode surface and, after solvent evaporation, the sample-modified electrode was inserted into the electrochemical cell and electrochemical runs were performed. Air-saturated $0.25 \mathrm{M}$ acetic acid/sodium acetate (Panreac reagents, in the following termed $\mathrm{HAc} / \mathrm{NaAc}$ ) aqueous solution at $\mathrm{pH} 4.75$ was used as a supporting electrolyte. Semi-derivative convolution of data was performed with CHI660D software to increase peak resolution. Current measurements were taken at intervals of $4 \mathrm{mV}$, no noise reduction procedure was applied.

\section{Results and discussion}

\section{Electrochemical response}

Fig. 1 compares the initial positive-going cyclic voltammograms, after semi-derivative convolution, of microparticulate deposits on GCE of ethanolic extracts of leaves of seedling of (a) Dittrichia viscosa and (b) Limbarda crithmoides after 7 days of germination in contact with air-saturated $0.25 \mathrm{M} \mathrm{HAc} / \mathrm{NaAc}$ buffer at $\mathrm{pH}$ 4.75. In the initial anodic scan, the voltammogram shows oxidation peaks at $c a$. 0.25 and $0.65 \mathrm{~V}$ (all labeled as $\mathrm{A}_{\mathrm{A}}$ ) preceding the rising current at $c a .1 .0 \mathrm{~V}$ corresponding to the oxygen evolution reaction. In the subsequent cathodic scan, only one well-defined reduction peak appears at $0.20 \mathrm{~V}\left(\mathrm{C}_{\mathrm{A}}\right)$ preceding the prominent cathodic wave at around $-0.6 \mathrm{~V}\left(\mathrm{C}_{\mathrm{ox}}\right)$ which can be attributed to the reduction of dissolved oxygen, as judged by blank experiments at unmodified GCEs. This signal is coupled with a weak anodic wave at $c a$. $-0.25 \mathrm{~V}\left(\mathrm{~A}_{\mathrm{ox}}\right)$ which can

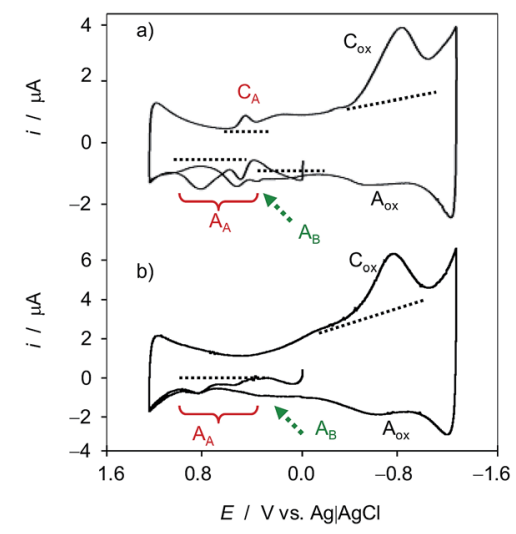

Fig. 1 Cyclic voltammograms of microparticulate films of ethanolic extracts of leaves of seedlings of (a) Dittrichia viscosa and (b) Limbarda crithmoides deposited on GCE in contact with air-saturated $0.25 \mathrm{M}$ $\mathrm{HAc} / \mathrm{NaAc}$ buffer at $\mathrm{pH} 4.75$ after 7 days of germination. Potential scan initiated at $0.0 \mathrm{~V} v \mathrm{vs} . \mathrm{Ag} / \mathrm{AgCl}$ in the positive direction; potential scan rate $50 \mathrm{mV} \mathrm{s}^{-1}$. Semi-derivative data convolution was carried out to enhance peak resolution. Dotted lines mark the base lines used for peak current measurements. in principle be attributed to the reversal of the first electron transfer in the reduction of dissolved $\mathrm{O}_{2}$ (vide infra). Interestingly, in the second anodic scan, the signals $\mathrm{A}_{\mathrm{A}}$ are weakened and are accompanied by additional signals between -0.25 and $0.05 \mathrm{~V} \mathrm{~A}_{\mathrm{B}}$, marked by a dotted arrow in Fig. 1 .

The observed voltammetric signals can in principle be described in terms of solid-state, proton-assisted electron transfer processes when the reactant and the product compounds are insoluble in the electrolyte. Under our experimental conditions, one can expect a frequent partial solubility of such (or one) components so that there is, to some extent, a solution-like electrochemistry, thus prompting the analysis of reaction kinetics based on voltammetric data (vide infra). In these circumstances, one can expect that the concentration in the vicinity of the electrode remains sufficiently high to ensure an equally sensitive response at the time scale of the voltammetric experiments.

The studied species are rich in secondary compounds such as flavonoids, sesquiterpenes and essential oils..$^{35-40,48-50}$ In the case of $D$. viscosa it has been reported that the concentration of leaf exudate phenolics increases under water stress. ${ }^{50}$ In a recent work, Kheyar-Kraouche et al. ${ }^{19}$ study by HPLC-MS the composition and antioxidant activity of an ethanolic extract of D. viscosa leaves, identifying phenolic acids, flavonoids, terpenoids and one lignan. Among them, rhamnetin, rosmarinic acid, (epi)-gallocatechin-gallate and costic acid, and different derivatives of caffeic acid and dicaffeoylquinic acid appear as particularly abundant. Accordingly, the signals $A_{A}, A_{B}$ can be attributed to the superposition of the oxidation processes of polyphenolic compounds, being dominated by the two-proton, two-electron oxidation of $o$-catechol units to the corresponding $o$-quinones. The recorded voltammetric response is consistent with that recorded in solutions of 3,5-dicaffeoylquinic acid displaying one oxidation wave at $0.45 \mathrm{~V}$ (see Fig. S1 in ESI $\dagger$ ). In agreement with literature, ${ }^{51}$ the electrochemical oxidation of dicaffeoylquinic acids is schematized in Fig. 2.

Under our experimental conditions, the reduction of dissolved oxygen at potentials more negative than $-0.60 \mathrm{~V}$, ultimately yielding $\mathrm{H}_{2} \mathrm{O}_{2}$, can produce different intermediate ROS, ${ }^{52,53}$ namely, superoxide radical anion $\left(\mathrm{O}_{2}{ }^{-}\right)$, hydroperoxide radical $\left(\mathrm{HO}_{2}^{\circ}\right)$, and hydroxyl radical ( $\mathrm{HO}^{\circ}$ ) (see ESI, Scheme S.1†) able to react with antioxidant polyphenolics. The appearance of new anodic signals after generation of $\mathrm{H}_{2} \mathrm{O}_{2}$ and other ROS can be attributed to the formation of new oxidizable compounds, responsible, as described for quercetin, ${ }^{22,23,54-57}$ of

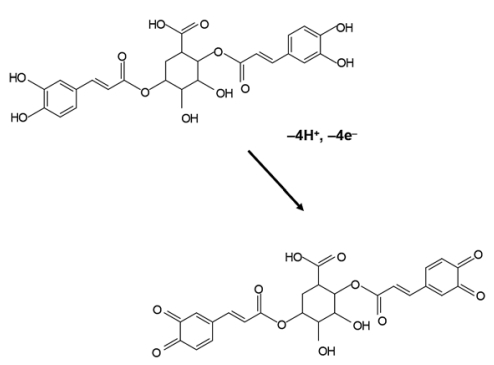

Fig. 2 Scheme for the electrochemical oxidation of dicaffeoylquinic acid in contact with aqueous electrolytes. 
the appearance of new voltammetric signals in the $2^{\text {nd }}$ anodic scan. This was confirmed by the initial anodic scan voltammograms of plant extracts in contact with $\mathrm{H}_{2} \mathrm{O}_{2}$ solutions in acetate buffer (see ESI, Fig. S2 $\dagger$ ).

The voltammetric features associated to ROS reactivity can be clearly seen in Fig. 3 where positive-going square wave voltammograms of seedlings of $D$. viscosa after 7 days of germination in contact with air-saturated acetate buffer initiated at different potentials are shown. When the potential scan is initiated at -0.25 (no ROS generation) and $-0.75 \mathrm{~V}$ (where it is expected low ROS generation), and common anodic signals at ca. $0.10\left(\mathrm{~A}_{\mathrm{Aa}}\right), 0.35\left(\mathrm{~A}_{\mathrm{Ab}}\right)$ and $0.85 \mathrm{~V}\left(\mathrm{~A}_{\mathrm{Ac}}\right)$ are recorded, the unique difference being the enhancement of the signal $A_{A b}$ relative to the signal $A_{\mathrm{Aa}}$ when ROS are generated. When the potential scan is initiated at $-1.25 \mathrm{~V}$, at which there is significant ROS generation, the enhancement of $\mathrm{A}_{\mathrm{Ab}}$ relative to $\mathrm{A}_{\mathrm{Aa}}$ is more pronounced, the signal $A_{a c}$ is significantly enhanced and a new signal appears at $-0.50 \mathrm{~V}\left(\mathrm{~A}_{\mathrm{B}}\right)$.

\section{Theoretical modeling}

The above voltammetric features can be interpreted on the basis of a simplified reaction model based on two simplifying assumptions: (I) the electrochemical response can be treated as occurring in solution phase; (II) the chemical reactions between electroactive components of plant extracts and ROS electrochemically generated can be treated as occurring in a homogeneous solution. Then, two basic hypotheses will be made:

(a) The vegetal extract contains a series of electroactive species, $P$, responsible for the signals $A_{A} / C_{A}$, each one containing a certain concentration $c_{\mathrm{P}}$ in the same.

(b) Some of such species react with ROS electrochemically generated giving rise to new species some of which being electrochemically responsive yielding the $A_{B}$ signals. As a result, the concentration of the parent vegetal species will decrease with time whereas the concentration of new species will increase.

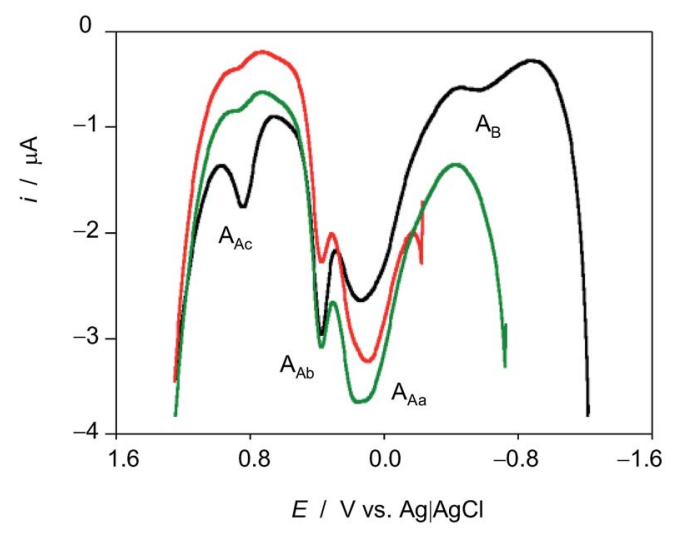

Fig. 3 Square wave voltammograms of microparticulate films of ethanolic extracts of leaves of seedlings of Dittrichia viscosa, on GCE in contact with air-saturated $0.25 \mathrm{M} \mathrm{HAc/NaAc}$ buffer at $\mathrm{pH} 4.75$ after 7 days of germination. Potential scan initiated at -0.25 (red), -0.75 (green) y $-1.25 \mathrm{~V}$ (black) in the positive direction; potential step increment $4 \mathrm{mV}$, square wave amplitude $25 \mathrm{mV}$, frequency $10 \mathrm{~Hz}$.
This treatment, however, neglects the influence of diffusion effects, the kinetics of the heterogeneous electron transfer of the oxidation of plant extract components, the kinetics and diffusive effects on electrochemical ROS generation, and the possibility of cross-reactions accompanying electron transfer processes. In regard to this last problem, it should be noted that the oxidation of $o$-catechol units to $o$-quinones involves a stepped mechanism (in aqueous media via ECEC or CECE pathways) forming intermediate semiquinones that can also undergo disproportionation reactions. Then, the ROS can react with the parent polyphenols but also with the intermediate semiquinones. Additionally, there is possibility of electropolymerization reactions coupled to such oxidation processes. Finally, the local pH decrease due to the hydrogen evolution reaction (HER) occurring at highly negative potentials can also influence ROS generation and reactivity.

This complex scenario is aggravated by the fact that the plant extracts contain a number of components (at least 51 have been identified in the ethanolic extracts of Dittrichia viscosa $)^{\mathbf{1 9}}$ most of them being electroactive. Accordingly, the following treatment can only be regarded as representative of an averaged plant response whose interest derives from (vide infra) its (i) discrimination between different species and (ii) possibility of correlation with saline stress.

The basic idea is that at the aforementioned electrochemical constraints operates at a short-time scale so that, at the time scale of voltammetric experiments between $5-500 \mathrm{mV} \mathrm{s}^{-1}$ measured intensity of the voltammetric signals can be taken as proportional to an effective concentration of the different species in the vicinity of the electrode and that these conditions are equivalent to those operating in conventional, solutionphase kinetics.

There is, however, one limitation: the amount of vegetal matter in the modified electrode cannot be accurately controlled. This influences not only the intensity of the A-peaks but also the generation of ROS. Accordingly, the kinetic model has to be reformulated in terms of relative concentrations in turn given by peak current ratios (i.e., relative intensities), normalizing the peak currents relative to the peak current of the process $\mathrm{C}_{\mathrm{ox}}$, as detailed below.

Repeatability of measurements was tested by performing three replicate measurements on freshly modified electrodes. The voltammetric profile was reproduced with dispersion of $\pm 5 \mathrm{mV}$ in the peak potentials and $\pm 20 \%$ in peak currents. These were measured using base lines as depicted in Fig. 1. In the case of overlapping peaks, the base line for the first peak was retained. In agreement with the previous considerations, however, the peak current ratios presented dispersions below $\pm 10 \%$ in replicate measurements.

To obtain (relative) peak current/time curves, the reaction time can be computed as the time between the appearance of the different voltammetric peaks. This time can be calculated as the quotient between the peak potential separation, $\Delta E$, and the potential scan rate, $v$, as $t=\Delta E / v$. Accordingly, experiments at different scan rates permit to obtain concentration ratios at different times. Qualitatively, experimental data agree with the foregoing set of considerations, as can be seen in Fig. 4, in 
which the variation of the peak current of the process $A_{B}$ at $0.05 \mathrm{~V}\left(I_{\mathrm{B}}(2)\right)$ recorded in the second scan relative to the peak current of the process $\mathrm{A}_{\mathrm{A}}$ at $0.25 \mathrm{~V}$ recorded in the first scan $\left(I_{\mathrm{A}}(1)\right)$ and in experiments such as in Fig. 1 and the variation of this last quantity relative to the peak current of the process $\mathrm{C}_{\mathrm{ox}}$ in the first cathodic scan, $I_{\mathrm{ox}}(1)$, are depicted for seedlings of Dittrichia viscosa after 7 days of germination.

Thus, let us consider that the vegetal extract contains an electroactive species A whose anodic signal $\mathrm{A}_{\mathrm{A}}$ is recorded in the initial anodic scan. Now, let us assume that this species reacts with electrochemically generated ROS. On first examination, the kinetic equation can be described in terms of a $2^{\text {nd }}$-order rate equation:

$$
\frac{\mathrm{d}[\mathrm{A}]}{\mathrm{d} t}=-k_{\mathrm{A}}[\mathrm{A}][\mathrm{ROS}]
$$

$k_{\mathrm{A}}$ being the rate constant. In view of the amplitude of the simplifying assumptions used in this study, this rate constant, as all others in the following has to be considered as apparent. Assuming that initially there are concentrations $c_{\mathrm{A}}$ and $c_{\mathrm{ROS}}$ of these species, the above equation can be written as:

$$
\frac{\mathrm{d} x}{\mathrm{~d} t}=k_{\mathrm{A}}\left(c_{\mathrm{A}}-x\right)\left(c_{\mathrm{ROS}}-x\right)
$$

where $x$ represents the concentration of the species formed as a result of the reaction of $\mathrm{A}$ with ROS. Integration of this equation yields:

$$
\ln \left(\frac{1-x / c_{\mathrm{A}}}{1-x / c_{\mathrm{ROS}}}\right)=\left(c_{\mathrm{A}}-c_{\mathrm{ROS}}\right) k_{\mathrm{A}} t
$$

Voltammetric data can be used to test the kinetics of the reaction of A with ROS considering that the peak current of the process $\mathrm{A}, I_{\mathrm{A}}(\mathrm{J})$, at the $\mathrm{J}$-scan is proportional to the local concentration of $\mathrm{A}$ at the corresponding time, $[\mathrm{A}]_{\mathrm{J}} ;$ i.e.: $I_{\mathrm{A}}(\mathrm{J})=$ $g_{\mathrm{A}}[\mathrm{A}]_{\mathrm{J}}, g_{\mathrm{A}}$ being an electrochemical constant depending on the potential scan rate, electrolyte, etc. Then, the initial

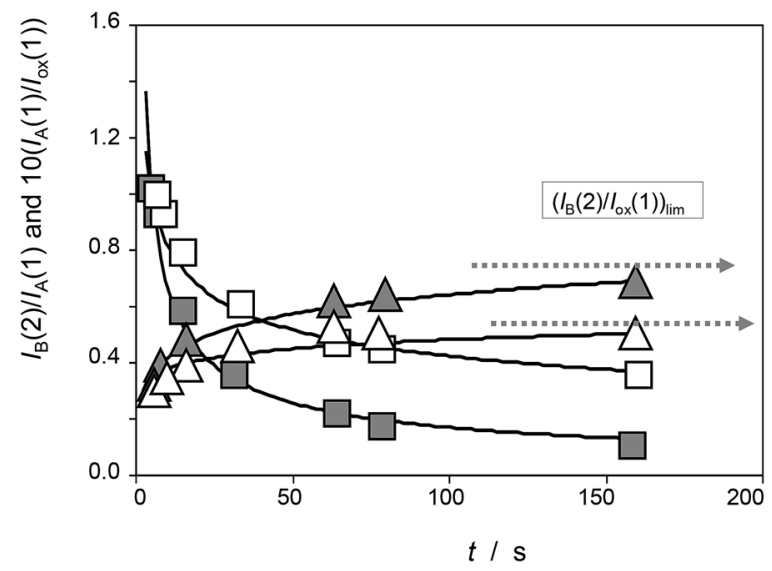

Fig. 4 Time variation of the peak current ratios $I_{A}(1) / I_{\text {ox }}(1)$ (squares) and $I_{B}(2) / I_{A}(1)$ (triangles) recorded in experiments such as in Fig. 1 for seedlings of Dittrichia viscosa after 7 days of germination in the absence of salinity (grey figures) and in $100 \mathrm{mM} \mathrm{NaCl}$ (empty figures) in the substrate. Continuous lines correspond to the fit of experimental data points to potential functions. concentration $c_{\mathrm{A}}$ can correspond to the peak current recorded in the initial anodic scan, $I_{\mathrm{A}}(1)=g_{\mathrm{A}} c_{\mathrm{A}}$, and the $x / c_{\mathrm{A}}$ ratio at the time passed between the generation of ROS and the appearance of the A-centered oxidation peak in the second scan will be:

$$
\frac{x}{c_{\mathrm{A}}}=1-\frac{I_{\mathrm{A}}(2)}{I_{\mathrm{A}}(1)}
$$

In turn, one can assume that the initial concentration of ROS is proportional to the peak current for the process $\mathrm{C}_{\mathrm{ox}}$ recorded in the first cathodic scan, $I_{\text {ox }}(1)$, measured in the corresponding voltammetric experiment; i.e.: $I_{\mathrm{Ox}}(1)=g_{\mathrm{ROS}} c_{\mathrm{ROS}}$. Then, the $x / c_{\mathrm{ROS}}$ ratio can be calculated as:

$$
\frac{x}{c_{\mathrm{ROS}}}=\frac{g_{\mathrm{ox}}}{g_{\mathrm{A}}}\left(\frac{I_{\mathrm{A}}(1)-I_{\mathrm{A}}(2)}{I_{\mathrm{ox}}(1)}\right)
$$

In the more favorable case, the ratio between the electrochemical constants $g_{\mathrm{A}}$ and $g_{\mathrm{ROS}}$ can be considered as close to unit so that eqn (3) can be rewritten as:

$$
\ln \left(\frac{\frac{I_{\mathrm{A}}(2)}{I_{\mathrm{A}}(1)}}{1-\frac{I_{\mathrm{A}}(1)-I_{\mathrm{A}}(2)}{I_{\mathrm{OX}}(1)}}\right)=\ln I=\left(c_{\mathrm{A}}-c_{\mathrm{ROS}}\right) k_{\mathrm{A}} t
$$

This equation can be tested with experimental data. Thus, Fig. 5 shows the plots of $\ln I$ vs. $t$ for the reaction of the electroactive component responsible for the peak at $0.25 \mathrm{~V}\left(\mathrm{~A}_{\mathrm{A}}\right)$ with electrochemically generated ROS from experiments such as in Fig. 1 performed at different scan rates for seedlings of Dittrichia viscosa and Limbarda crithmoides growth in the absence and in the presence of salinity in the culture substrate.

In agreement with the expectances from eqn (6), in all cases, plots of $\ln I$ vs. $t$ were satisfactorily fitted to straight lines with

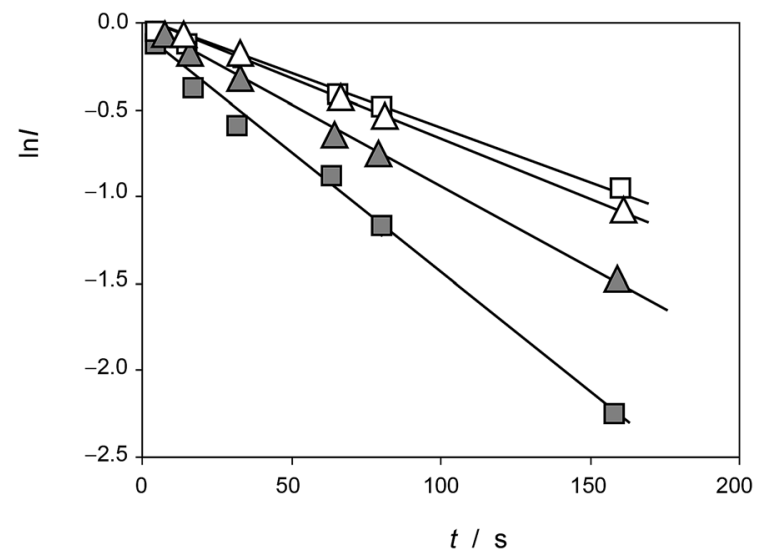

Fig. 5 Plots of $\ln / \mathrm{Vs}$. $t$ for the reaction of the electroactive component responsible for the peak at $0.25 \mathrm{~V}\left(\mathrm{~A}_{\mathrm{A}}\right)$ with electrochemically generated ROS from experiments such as in Fig. 1. Solid squares: Dittrichia viscosa seedlings growth in the absence of salinity; squares: Dittrichia viscosa seedlings growth in $100 \mathrm{mM} \mathrm{NaCl}$ solution; solid triangles: Limbarda crithmoides seedlings growth in the absence of salinity; triangles: Limbarda crithmoides seedlings growth in $100 \mathrm{mM} \mathrm{NaCl}$ in the germination medium. 
ordinate at the origin near to zero. The slope of these lines yields an apparent rate constant, $k_{\mathrm{A}}^{\text {app }}$, equal to $\left(c_{\mathrm{A}}-c_{\mathrm{ROS}}\right) k_{\mathrm{A}}$. Table 1 summarizes the statistical parameters for kinetic data in this study based on the signal $\mathrm{A}_{\mathrm{Aa}}$ in voltammograms such as in Fig. 1 and 2 using data treatment in eqn (6).

A second way for validating the proposed model is the evaluation of the time variation of the products of reaction between the pristine plant components and the electrochemically generated ROS. Now, let us consider a species B which is formed as a result of the reaction of a precursor species, $\mathrm{P}$, in the plant with electrochemically generated ROS. Making similar assumptions as before, the $2^{\text {nd }}$ order kinetic equation is:

$$
\frac{\mathrm{d}[\mathrm{B}]}{\mathrm{d} t}=-k_{\mathrm{B}}[\mathrm{P}][\mathrm{ROS}]
$$

Assuming that the reaction of formation of B involves a $1: 1$ stoichiometric ratio for $\mathrm{P}$ and $\mathrm{B}$, the kinetic equation becomes:

$$
\frac{\mathrm{d} x}{\mathrm{~d} t}=k_{\mathrm{B}}\left(c_{\mathrm{P}}-x\right)\left(c_{\mathrm{ROS}}-x\right)
$$

$c_{\mathrm{P}}$ being the initial concentration of the precursor in the vicinity of the electrode and $x$ the concentration of the reaction product $\mathrm{B}$ at a time $t$. Integration of eqn (8) yields:

$$
\ln \left(\frac{1-x / c_{\mathrm{P}}}{1-x / c_{\mathrm{ROS}}}\right)=\left(c_{\mathrm{P}}-c_{\mathrm{ROS}}\right) k_{\mathrm{B}} t
$$

As before, experiments such as in Fig. 1 will be considered. Then, the peak current recorded in the second anodic scan for the product $\mathrm{B}, I_{\mathrm{B}}(2)$, will be proportional to the concentration of this compound, $x$ :

$$
x=\frac{I_{\mathrm{B}}(2)}{g_{\mathrm{B}}}
$$

Then, the $x / c_{\text {Ros }}$ ratio will be

$$
\frac{x}{c_{\mathrm{ROS}}}=\frac{\frac{I_{\mathrm{B}}(2)}{g_{\mathrm{B}}}}{\frac{I_{\mathrm{ox}}(1)}{g_{\mathrm{ox}}}}=\frac{g_{\mathrm{ox}}}{g_{\mathrm{B}}} \frac{I_{\mathrm{B}}(2)}{I_{\mathrm{ox}}(1)}
$$

Notice that, strictly, $g_{\text {ox }}$, which refers to a diffusion-limited process, is not equivalent to $g_{\mathrm{A}}, g_{\mathrm{B}}$, in principle corresponding to diffusion-controlled processes. Assuming that the reaction of formation of $\mathrm{B}$ involves a $1: 1$ stoichiometric ratio for $\mathrm{P}$ and $\mathrm{B}$, one can assume that $I_{\mathrm{B}}(1)$ must tend to a limiting value corresponding to the total conversion of $\mathrm{P}$ into $\mathrm{B}$. Then:

Table 1 Statistical parameters for kinetic data in this study based on the signal $A_{A a}$ in voltammograms such as in Fig. 1 using data treatment in eqn (6). SL: slope; OO: ordinate at the origin

\begin{tabular}{lccl}
\hline Species & SL $\left(k_{\mathrm{A}}^{\mathrm{app}}\right) / \mathrm{s}^{-1}$ & OO & $r$ \\
\hline L. crithmoides & $0.00912 \pm 0.00007$ & $-0.044 \pm 0.005$ & 0.9998 \\
D. viscosa & $0.0138 \pm 0.0006$ & $-0.06 \pm 0.04$ & 0.995 \\
I. helenium & $0.0415 \pm 0.0008$ & $-0.08 \pm 0.04$ & 0.993
\end{tabular}

$$
c_{\mathrm{P}}=\frac{I_{\mathrm{B}}^{\lim }(2)}{g_{\mathrm{B}}}
$$

Since, as previously indicated, the absolute values of the peak currents vary with the net amount of sample deposited onto the electrode, the $x / c_{\mathrm{P}}$ ratio can be calculated from the limiting value of the $I_{\mathrm{B}}(2) / I_{\mathrm{ox}}(1)$ ratio, $\left(I_{\mathrm{B}}(2) / I_{\mathrm{ox}}(1)\right)_{\text {lim }}$, determined in curves such as in Fig. 4 . Then:

$$
\frac{x}{c_{\mathrm{P}}}=\frac{\frac{I_{\mathrm{B}}(2)}{I_{\mathrm{oX}}(1)}}{\left(\frac{I_{\mathrm{B}}(2)}{I_{\mathrm{ox}}(1)}\right)_{\lim }}
$$

Assuming, as before, that the $g_{\text {ox }} / g_{\text {B }}$ ratio approaches unit, one obtains.

$$
\ln \left(\frac{1-\frac{I_{\mathrm{B}}(2) / I_{\mathrm{ox}}(1)}{I_{\mathrm{B}}(2) / I_{\mathrm{ox}}(1)_{\lim }}}{1-\frac{I_{\mathrm{B}}(2)}{I_{\mathrm{ox}}(1)}}\right)=\ln F=\left(c_{\mathrm{P}}-c_{\mathrm{Ros}}\right) k_{\mathrm{B}} t
$$

This equation can be tested experimentally using data such as in Fig. 4. The corresponding $\ln F v s$. $t$ representations for seedlings of $D$. viscosa seedlings growth in the absence of salinity (grey squares) and in $100 \mathrm{mM} \mathrm{NaCl}$ in the culture substrate (squares) are depicted in Fig. 6. Again, a satisfactory linearity was obtained in agreement with theoretical expectances from eqn (14), the slope of the corresponding representations providing the apparent rate constant, $k_{\mathrm{B}}^{\mathrm{app}}\left(=c_{\mathrm{P}}-c_{\mathrm{ROS}}\right)$ $k_{\mathrm{B}}$. Table 2 summarizes the statistical parameters for the studied seedlings.

\section{Influence of salinity}

Fig. 7 shows the cyclic voltammograms of microparticulate films of ethanolic extracts of seedlings of Inula helenium in contact with air-saturated aqueous acetate buffer after 7 days of

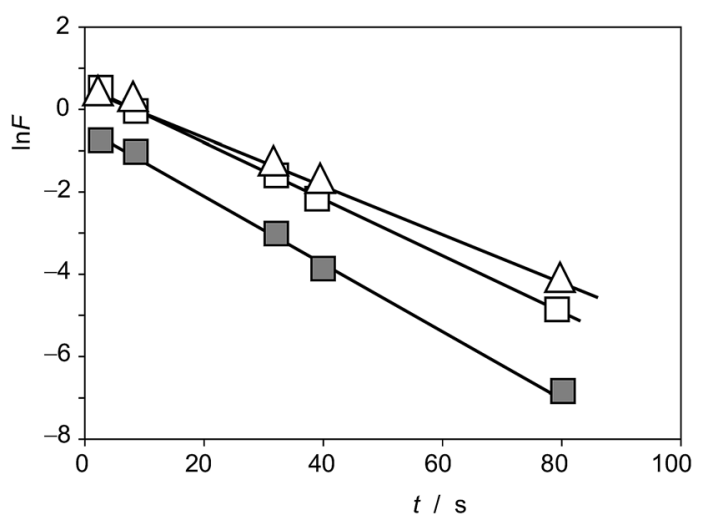

Fig. 6 Plots of $\ln F$ vs. $t$ for the formation of the electroactive component responsible for the peak at $0.05 \mathrm{~V}\left(\mathrm{~A}_{B}\right)$ in the voltammograms of Dittrichia viscosa seedlings growth in the absence of salinity (grey squares) and in $100 \mathrm{mM} \mathrm{NaCl}$ in the germination medium (squares), and Inula helenium (triangles), based on voltammetric data such as in Fig. 1. 
Table 2 Statistical parameters for kinetic data in this study based on the signal $A_{B}$ in voltammograms such as in Fig. 1 using data treatment in eqn (14)

\begin{tabular}{llrr}
\hline Species & SL $\left(k_{\mathrm{B}}^{\mathrm{app}}\right) / \mathrm{s}^{-1}$ & \multicolumn{1}{l}{ OO } & \multicolumn{1}{c}{$r$} \\
\hline L. crithmoides & $0.0799 \pm 0.0010$ & $-0.52 \pm 0.04$ & 0.9998 \\
D. viscosa & $0.0684 \pm 0.0017$ & $0.69 \pm 0.07$ & 0.9990 \\
I. helenium & $0.0600 \pm 0.0015$ & $0.51 \pm 0.06$ & 0.9990
\end{tabular}

germination (a) in the absence of salinity and in (b) $100 \mathrm{mM}$ and (c) $300 \mathrm{mM} \mathrm{NaCl}$ in the culture substrate. On increasing salinity, there is a decrease of the signals $\mathrm{A}_{\mathrm{Aa}}$ and $\mathrm{A}_{\mathrm{Ab}}$ as well as the decrease or even disappearance of the signals $A_{B}$ associated to the products of the reaction with ROS of the original vegetal components. This means that the saline stress affects to the electroactive components of the plants.

A first evaluation of the influence of salinity can be derived from the variation of the ratio between the signals $A_{o x}$ and $C_{o x}$, $I\left(\mathrm{~A}_{\text {ox }}\right) / I_{\text {ox }}(1)$. As previously noted, and following literature, ${ }^{48,49}$ the reduction of dissolved oxygen at carbon electrodes (process $\mathrm{C}_{\mathrm{ox}}$ in Fig. 1 and 7) follows a multi-step pathway initiated by the one-electron reduction of $\mathrm{O}_{2}$ to yield radical anion superoxide. This experiences rapidly different reactions (protonation, disproportionation) partially yielding hydroperoxide and hydroxyl radicals, but the remaining $\mathrm{O}_{2}{ }^{--}$will be electrochemically re-oxidized to $\mathrm{O}_{2}$ through the process $\mathrm{A}_{\mathrm{ox}}$. According to this interpretation, the reaction of the plant components with electrochemically generated $\mathrm{O}_{2}{ }^{-}-$will produce an additional decrease of the $I\left(\mathrm{~A}_{\mathrm{ox}}\right) / I_{\text {ox }}(1)$ ratio.

Fig. 8 depicts the variation of the $I\left(\mathrm{~A}_{\mathrm{ox}}\right) / I_{\mathrm{ox}}(1)$ ratio with $I_{\mathrm{ox}}(1)$ for specimens of Dittrichia viscosa after 7 days of germination in

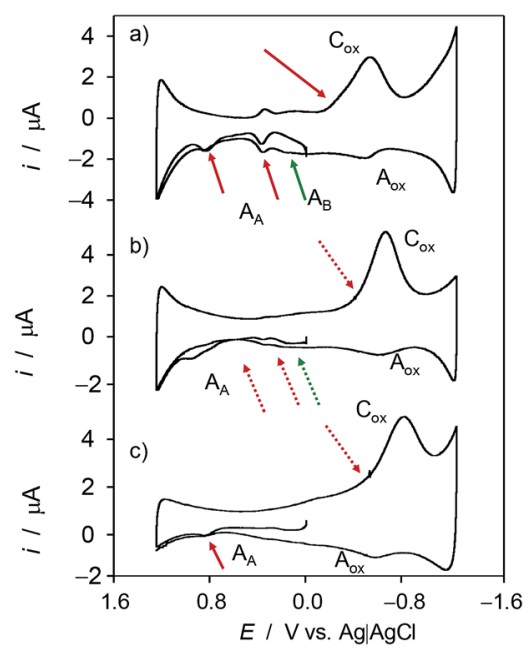

Fig. 7 Cyclic voltammograms of microparticulate films of ethanolic extracts of seedlings of Inula helenium deposited on GCE in contact with air-saturated $0.25 \mathrm{M} \mathrm{HAc/NaAc}$ buffer at $\mathrm{pH} 4.75$ after 7 days of germination: (a) in the absence of salinity and in the presence of (b) $100 \mathrm{mM}$ and (c) $400 \mathrm{mM} \mathrm{NaCl}$ in the substrate. Potential scan initiated at $0.0 \mathrm{~V}$ vs. $\mathrm{Ag} / \mathrm{AgCl}$ in the positive direction; potential scan rate $50 \mathrm{mV}$ $\mathrm{s}^{-1}$. Semi-derivative data convolution was carried out to enhance peak resolution. culture substrates having different $\mathrm{NaCl}$ concentrations. This representation is equivalent to the variation of the peak current ratio with the time of reaction between electrochemically generated $\mathrm{O}_{2}{ }^{--}$and other components in the electrode (plant components) and the solution, computed, as previously described, as the time passed between the peaks $\mathrm{C}_{\mathrm{ox}}$ and $\mathrm{A}_{\mathrm{ox}}$ in cyclic voltammograms at different potential scan rates $v$. To compensate the effect of the different amounts of plant extract deposited onto the electrode surface, $I_{\mathrm{ox}}(1)$ - which grows on increasing $v$; i.e., on decreasing time-, rather than time was used in the graph. As can be seen in Fig. 8, experimental data points can be fitted to salinity-dependent logarithmic curves, the $I\left(\mathrm{~A}_{\mathrm{ox}}\right) /$ $I_{\mathrm{ox}}(1)$ ratio decreasing with salinity. This means that the increase in salinity determines an increase of the reactivity of plant extracts with anion radical superoxide.

Interestingly, voltammetric data evidences the existence of differences between the three studied species in regard to their reactivity with ROS. Apart from the above features, these differences can be illustrated by the variation of the height of the signal $A_{B}$ in the second scan, $I_{B}(2)$, relative to the $\mathrm{C}_{\mathrm{Ox}}$ signal in the first cathodic scan, $I_{\mathrm{ox}}(1)$. The variation of the $I\left(\mathrm{~A}_{\mathrm{B}}(2)\right)$ / $I\left({ }_{\text {ox }}(1)\right)$ ratio on the time of reaction with electrochemically generated ROS for specimens of (a) Inula helenium, and (b) Dittrichia viscosa after 7 days of germination is depicted in Fig. 10. The $I\left(\mathrm{~A}_{\mathrm{B}}(2)\right) / I($ ox $(1))$ ratio decreases on increasing the time of reaction thus suggesting that the formation of the species responsible for the signal $A_{B}$ is more efficient at short times, as expected by the coexistence of other competing reactions with ROS.

Remarkably, the $I\left(\mathrm{~A}_{\mathrm{B}}(2)\right) / I\left({ }_{\text {ox }}(1)\right)$ ratio in the absence of chloride ions is lower than in the $150 \mathrm{mM} \mathrm{NaCl}$ in the culture substrate for Inula helenium (Fig. 9a), whereas the contrary effect was observed for Dittrichia viscosa (Fig. 9b) and Limbarda crithmoides. This means that, even with a common pattern of reactivity with ROS, there are clear individual differences in the effect of salinity on that reactivity.

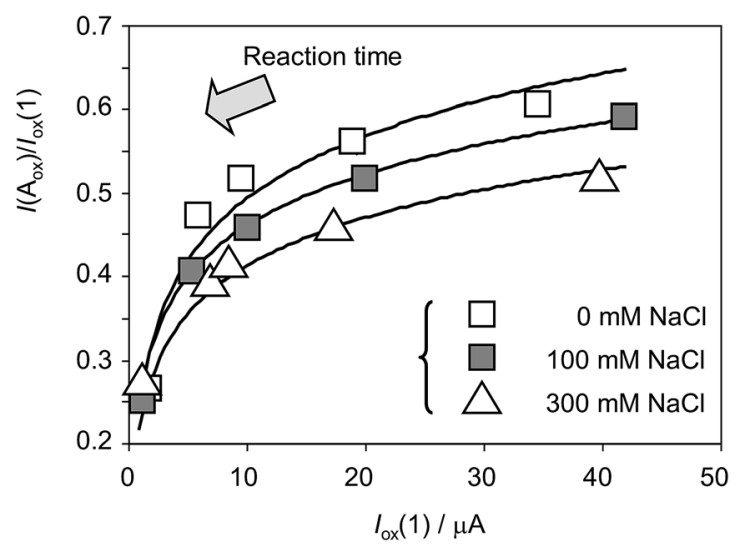

Fig. 8 Variation of the $I\left(A_{o x}\right) / I_{o x}(1)$ ratio with $I_{o x}(1)$ for specimens of Dittrichia viscosa after 7 days of germination in culture media having different $\mathrm{NaCl}$ concentrations. Experimental data from cyclic voltammograms in the conditions such as those in Fig. 1 and 7. Continuous lines represent the fit of such data to logarithmic dependences. The arrow marks the variation of the ROS reaction time (see text). 

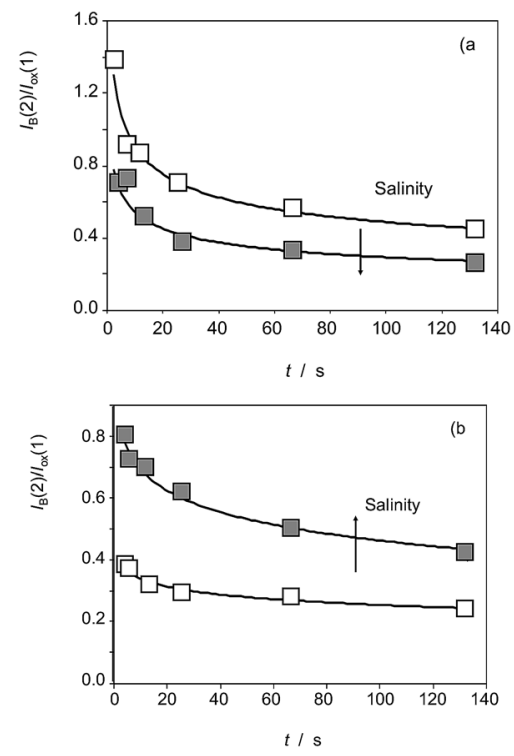

Fig. 9 Variation of the $\left./\left(A_{B}(2)\right) / /_{\text {ox }}(1)\right)$ ratio on the time of reaction with electrochemically generated ROS for specimens of (a) Inula helenium, and (b) Dittrichia viscosa after 7 days of germination in the absence of chloride ions (empty squares) and in $150 \mathrm{mM} \mathrm{NaCl}$ (solid squares) in the substrate. From cyclic voltammograms in the conditions such as those in Fig. 1 and 7. Continuous lines correspond to the fit of experimental data to exponential curves.

These results can be considered as consistent with data in Fig. 5 and 6, where salinity-dependent graphs were obtained for the reactivity with ROS of plant components. According to eqn
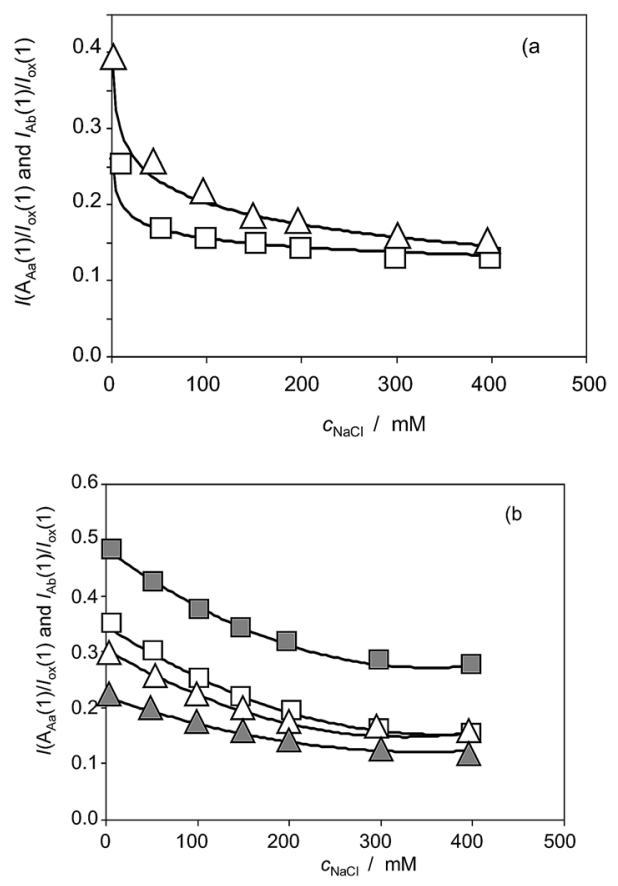

Fig. 10 (a) Variation of the $\left./\left(A_{A a}(1)\right) / / /_{o x}(1)\right)$ (squares) and $\left./\left(A_{A b}(1)\right) / / /_{o x}(1)\right)$ (triangles) ratios on the $\mathrm{NaCl}$ concentration for Inula helenium specimens after 7 days of germination. From cyclic voltammograms in the conditions such as those in Fig. 1 and 7. (b) The same representation for specimens of Dittrichia viscosa (solid figures) and Limbarda crithmoides (empty figures).
(6) and (14), the slope of the linear $\ln I$ and $\ln F v$ s. time representations depend on the rate constant and the initial concentration of ROS and the parent components of the plant. Accordingly, one can expect that $c_{\mathrm{A}}$ and $c_{\mathrm{P}}$ were dependent on the time of germination and the salinity and that such dependency can be monitored from voltammetric data. Under our experimental conditions, one can expect that the unique (or at least the principal contribution) difference was due to the initial concentration of the plant components; i.e., that $c_{\mathrm{A}}$ and $c_{\mathrm{P}}$ were function of the salinity of the culture substrate.

In this scenario, voltammetric data can also provide information on the influence of the salinity on the generation of these plant components based on the hypotheses:

(a) The seedlings generate in the initial stages of the germination several electroactive species $P$ whose concentration reaches a mature value $c_{\mathrm{P}}$ which remains essentially unchanged when seedlings are formed.

(b) The rate constant for the formation of $\mathrm{P}$ will be dependent on the salinity of the medium and other factors. If all these other factors remain unaltered, the rate constant, $k_{\mathrm{G}}$, in the absence of salinity will differ than the salinity-dependent rate constants, $k_{\mathrm{GS}}$.

Since voltammetric data are only available when the seeds have been germinated, there is no possibility of determining the concentration $c$ of the electroactive species at different germination times $\left(t_{\mathrm{G}}\right)$; i.e., only the mature concentration $c_{\mathrm{P}}$ is available.

Fig. 10a shows the variation of the $I\left(\mathrm{~A}_{\mathrm{Aa}}(1)\right) / I\left(\mathrm{C}_{\mathrm{ox}}(1)\right)$ and $I\left(\mathrm{~A}_{\mathrm{Ab}}(1)\right) / I\left(\mathrm{C}_{\mathrm{ox}}(1)\right)$ ratios on the $\mathrm{NaCl}$ concentration $\left(c_{\mathrm{NaCl}}\right)$ in the voltammograms recorded for Inula helenium specimens after 7 days of germination. One can see that the above peak current ratios decrease monotonically with the salinity thus denoting that there is a decrease in the capacity of the plant to generate such components. Fig. 10b shows the same representation for extracts of seedlings of Dittrichia viscosa and Limbarda crithmoides. Although the voltammetric pattern was similar, there are differences between the tendency graphs of the different species.

Considering that the values of $I\left(\mathrm{~A}_{\mathrm{Aa}}(1)\right) / I\left(\mathrm{C}_{\mathrm{ox}}(1)\right)$ and $I\left(\mathrm{~A}_{\mathrm{Ab}}(1)\right) /$ $I\left(\mathrm{C}_{\mathrm{ox}}(1)\right)$ ratios extrapolated at time zero are, in principle, representative of the initial concentration of the components responsible for signals $A_{A a}$ and $A_{A b}$, the curves in Fig. 10 can be treated as representative of the influence of salinity in the composition of the different species.

\section{Correlation with germination data}

Concerning germination response, although all taxa followed the same pattern in relation to salt increasing concentrations, important differences in terms of tolerance level were observed depending on the species (Fig. 11, see also ESI, Tables S.1 to $\mathrm{S.} . \dagger)$. A decrease in germination percentage and velocity was observed from a critical $\mathrm{NaCl}$ concentration; salinity drastically affects plants above $300 \mathrm{mM}$, and, in fact, at $400 \mathrm{mM}$ there is practically no germination.

The most tolerant species were D. viscosa and L. crithmoides, specially this last taxon showed high tolerance to salt in the 

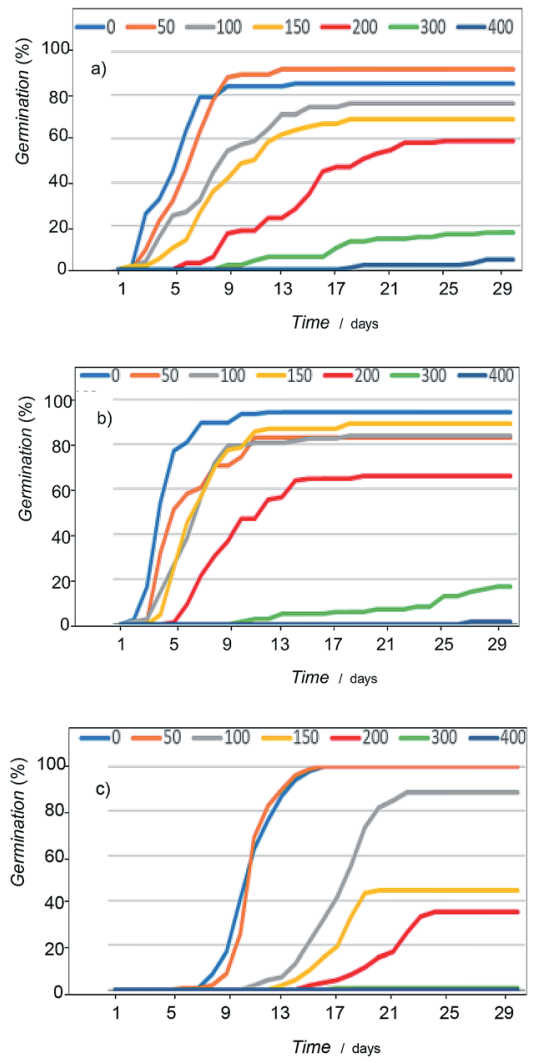

Fig. 11 Germination curves showing the variation of seed response to salinity of: (a) Dittrichia viscosa, (b) Limbarda crithmoides, and (c) Inula helenium.

range from 150 to $200 \mathrm{mM} \mathrm{NaCl}$ with higher germination percentage and velocity. I. helenium was more affected by the increasing concentration of salt in the culture substrate; both parameters, percentage and velocity of germination, fell significantly above $100 \mathrm{mM} \mathrm{NaCl}$ in respect to the control. Thus, differences between the three tested species, highlighted $L$. crithmoides as the species more tolerant to saline stress, followed by $D$. viscosa, whereas I. helenium is the most sensitive to salinity.

These results can be correlated with voltammetric data taking the variation of the intensity of the peak $\mathrm{A}_{\mathrm{A}}$ relative to the signal $\mathrm{C}_{\mathrm{ox}}$ with the salinity in the voltammograms. In principle, the more representative value of the $I_{\mathrm{A}}(1) / I_{\mathrm{ox}}(1)$ ratio would be that extrapolated at infinite time in curves such as depicted in Fig. 4; but taking into account the slow variation of this ratio with the reaction time at times above $100 \mathrm{~s}$, the values of the peak current ratio in cyclic voltammograms recorded at a potential scan rate of $20 \mathrm{mV} \mathrm{s}^{-1},\left[I_{\mathrm{A}}(1) / I_{\mathrm{ox}}(1)\right]_{20}$, were taken. Fig. 12 compares the variation of this ratio and the percentage of germination with the salinity for seedlings of $L$. crithmoides. Clearly, there is a parallel variation of both parameters with the concentration of $\mathrm{NaCl}$.

A second set of correlations can be obtained on comparing the response to salinity in Fig. 9 with germination data. As previously noted, the species more sensitive to saline stress as indicated by germination data (see Fig. 11), I. helenium, is also

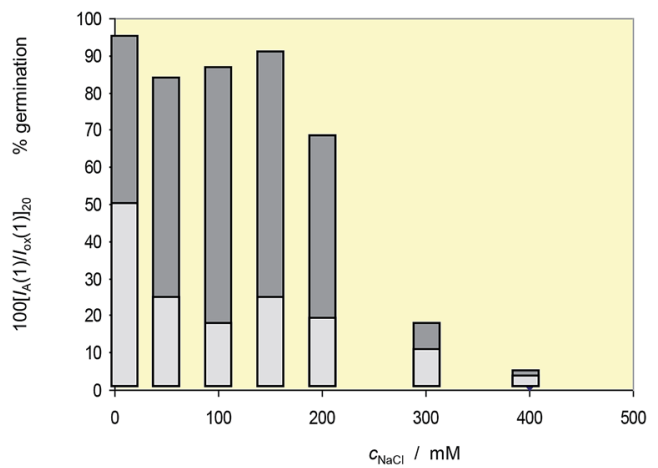

Fig. 12 Variation of the percentage of germination and the $\left[I_{A}(1) /\right.$ $\left.I_{\text {ox }}(1)\right]_{20}$ ratio with the $\mathrm{NaCl}$ concentration in the cultivation medium for seedlings of Limbarda crithmoides.

that producing a decrease in the reactivity with ROS, denoted by the lower formation of the compound responsible for peak $A_{B}$, as illustrated in Fig. 9. Consistently, the apparent rate constant for reaction with ROS (see Fig. 6 and Table 2) decreases in the order L. crithmoides $>$ D. viscosa $>I$. helenium.

\section{Voltammetric response of seedlings after recovery}

Recovery experiments were carried out by growing the seedlings in saline media and subsequently transferred to a non-saline medium. Recovery germination data showed significant differences in behavior between the compared species (Fig. 13, see also ESI, Table S5 $\dagger$ ). D. viscosa and L. crithmoides reached high germination values at the highest $\mathrm{NaCl}$ concentrations tested, exceeding (L. crithmoides) or equaling (D. viscosa) the values obtained in the control, whereas I. helenium only obtained high values at the lowest salt concentrations tested. These results revealed an ionic damage induced by exposure to high

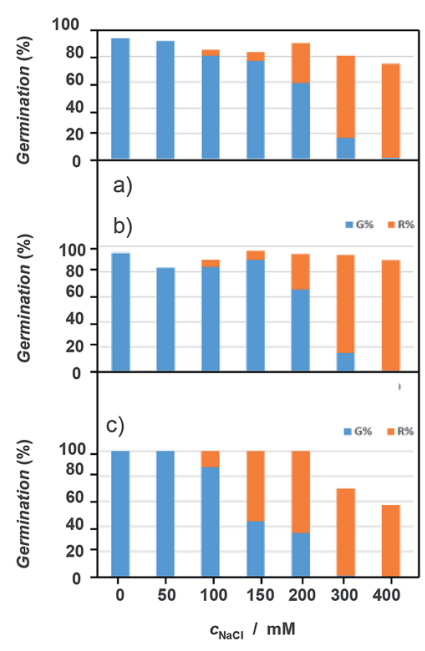

Fig. 13 Initial germination percentages (mean) indicating the salinity effect (blue), and total germination (orange) after transference of nongerminated seeds from $\mathrm{NaCl}$ solutions (mM) to distilled water (recovery). (a) Limbarda crithmoides, (b) Dittrichia viscosa, (c) Inula helenium. 
concentrations of salt in the species I. helenium, which is coherent with the germination tolerance observed in previously exposed results and the known ecology of this species.

Interestingly, voltammetric data suggests that, although there is satisfactory plant growth, the ability of the plant components to react with ROS is altered, being diminished, as illustrated in Fig. 14 where $I\left(\mathrm{~A}_{\mathrm{ox}}\right)$ vs. $I_{\mathrm{ox}}(1)$ plots for specimens of Inula helenium after 7 days of germination in culture media with $150 \mathrm{mM} \mathrm{NaCl}$ and after recovery in non-saline culture media, are depicted conjointly with data for the seedlings growth in the absence of salinity. The data points for seedlings growth in the absence of salinity define a common curve with those from the specimens after recovery whereas the data for seedlings growth in saline medium define a tendency curve below the above. These data denote that the ability to react with ROS has been recovered.

Similar analysis can be made on considering the voltammetric signals for the electroactive components in seedlings. The more interesting result can be seen in Fig. 15, where the variation of the $I_{\mathrm{Ac}}(1) / I_{\mathrm{ox}}(1)$ ratio with the concentration of $\mathrm{NaCl}$ in the culture media, $c_{\mathrm{NaCl}}$, for specimens of Limbarda crithmoides (green figures) and Inula helenium (red figures) after 7 days of germination in non-saline media (empty figures), and after recovery in non-saline culture media (solid figures), is depicted. The voltammetric peak $\mathrm{A}_{\mathrm{Ac}}$ increases on increasing the salinity of the substrate, thus suggesting that this signal is associated to some response of the plant to saline stress. Remarkably, the seedlings obtained by recovery after saline stress do not show the $I_{\mathrm{Ac}}(1) / I_{\mathrm{ox}}(1)$ ratio of the specimens growth in the absence of salinity; on the contrary, the recovered specimens display a value for this ratio almost identical to that measured in the non-recovered specimens. This feature suggests that the saline stress generates some metabolic defensive response that is maintained after the end of the stress.

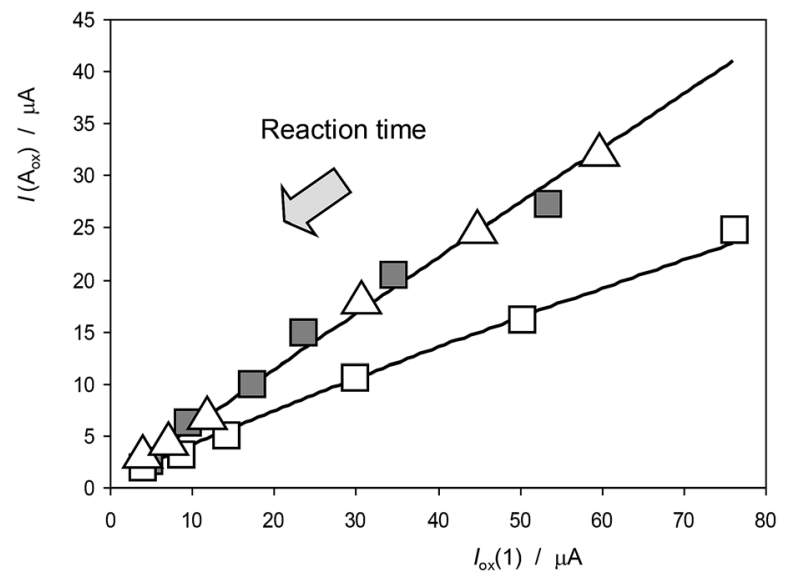

Fig. 14 Variation of the $I\left(A_{o x}\right)$ with $I_{o x}(1)$ for specimens of Inula helenium after 7 days of germination in non-saline media (solid squares), in a culture media with $100 \mathrm{mM} \mathrm{NaCl}$ (squares) and the above after recovery in non-saline culture media (triangles). Experimental data from cyclic voltammograms in the conditions such as those in Fig. 1 and 7. The arrow marks the variation of the ROS reaction time (see text).

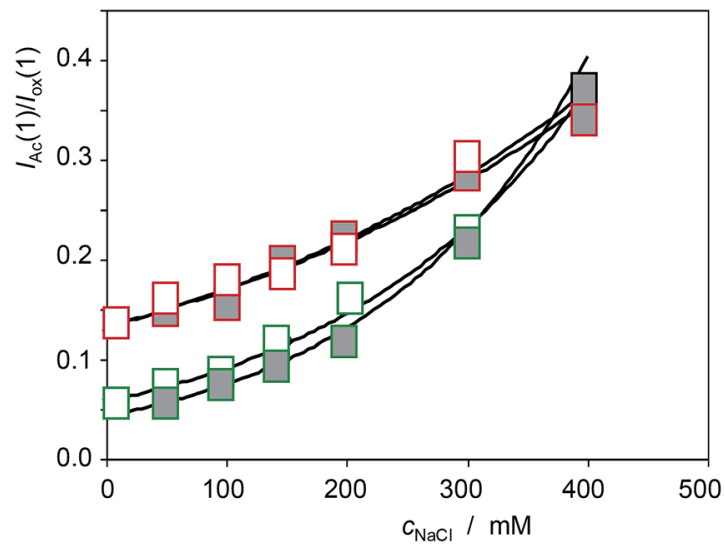

Fig. 15 Variation of the $I_{\mathrm{AC}}(1) / I_{\mathrm{Ox}}(1)$ ratio with the concentration of $\mathrm{NaCl}$ in the culture media, $\mathrm{C}_{\mathrm{NaCl}}$, for specimens of Limbarda crithmoides (green figures) and Inula helenium (red figures) after 7 days of germination in non-saline media (empty figures), and after recovery in non-saline culture media (solid figures). Experimental data from cyclic voltammograms in the conditions such as those in Fig. 1 and 7.

\section{Conclusions}

The voltammetric response of microparticulate deposits from ethanolic extracts of leaves of seedlings of Inula helenium, Dittrichia viscosa, and Limbarda crithmoides in contact with aqueous acetate buffer consists of anodic signals mainly corresponding to the oxidation of polyphenolic plant components. Applying sufficiently cathodic potential inputs to air-saturated electrolyte solutions generates reactive oxygen species (ROS) in the electrode surface reacting with the plant compounds allowing to study the reactivity between such species from voltammetric data.

Voltammetric data agree satisfactorily with a simple kinetic model assuming homogeneous second-order reaction between the polyphenolic components of plants and electrochemically generated ROS. This model permits to calculate apparent rate constants for this reaction which were found to be sensitive to the salinity of the substrate and the detection of differences between the three tested species. These results suggest that voltammetry can be used as an auxiliary analytical tool in botanic science in order to obtain 'direct' kinetic information on processes of seedling growth, reactivity with ROS, and the influence of the salinity on the above processes.

\section{Conflicts of interest}

There are no conflicts to declare.

\section{Acknowledgements}

Project CTQ2017-85317-C2-1-P, supported with Ministerio de Economía, Industria y Competitividad (MINECO), Fondo Europeo de Desarrollo Regional (ERDF) and Agencia Estatal de Investigación (AEI), is gratefully acknowledged. 


\section{Notes and references}

1 N. Iqbal, S. Shahid Umar and N. A. Kan, J. Plant Physiol., 2015, 178, 84.

2 M. A. Ahanger, N. S. Tomar, M. Tittal, S. Argal and R. M. Agarwal, Physiol. Mol. Biol. Plants, 2017, 23, 731.

3 V. H. Lokhande and P. Suprasanna, Prospects of halophytes in understanding and managing abiotic stress tolerance in Environmental adaptations and stress tolerance of plants in the era of climate change, Springer, New York, 2012, pp. 2956.

4 T. J. Flowers and T. D. Colmer, New Phytol., 2008, 179, 945.

5 U. Deinlein, A. B. Stephan, T. Horie, W. Luo, G. Xu and J. I. Schroeder, Trends Plant Sci., 2014, 19, 371.

6 R. Munns and M. Tester, Annu. Rev. Plant Biol., 2008, 59, 651.

7 H. Tsukagoshi, Curr. Opin. Plant Biol., 2016, 29, 57.

8 C. Antoniou, A. Savvides, A. Christou and V. Fotopoulos, Curr. Opin. Plant Biol., 2016, 33, 101.

9 J. M. Hansen, Y.-M. Go and D. P. Jones, Annu. Rev. Pharmacol. Toxicol., 2006, 46, 215.

10 M. Valko, D. Leibfritz, J. Moncol, M. T. D. Cronin, M. Mazurand and J. Telser, Int. J. Biochem. Cell Biol., 2007, 39, 44.

11 R. Mittler, Trends Plant Sci., 2002, 7, 405.

12 J. Qi, J. Wang, Z. Gong and J.-M. Zhou, Curr. Opin. Plant Biol., 2017, 38, 92.

13 R. Hilleary and S. Gilroy, Curr. Opin. Plant Biol., 2018, 43, 57. 14 K. J. O'Byrne and A. G. Dalgleish, Br. J. Cancer, 2001, 85, 473. 15 D. Gius and D. R. Spitz, Antioxid. Redox Signaling, 2006, 8, 1249.

16 A. Nunomura, K. Tabata, S. Chiba, M. A. Smith and G. Perry, in Oxidative Stress and Disease, ed. Y. Luo and L. Packer, CRC Press, Boca Raton, 2006, pp. 365-372.

17 E. A. Hillard, F. Caxico de Bareu, D. C. Melo Ferreira, G. Jaouen, M. O. Fonseca Goulart and C. Amatore, Chem. Commun., 2008, 2612.

18 B. Yang, A. Kotani, K. Arai and F. Kusu, Anal. Sci., 2001, 17, 599.

19 N. Kheyar-Kraouche, A. Bento da Silva, A. T. Serra, F. Bedjou and M. R. Bronze, J. Pharm. Biomed. Anal., 2018, 156, 297.

20 P. A. Kilmartin and C. F. Hsu, Food Chem., 2003, 82, 501.

21 Kh. Z. Brainina, A. V. Ivanova, E. N. Sharafutdinova, E. I. Lozovskaya and I. I. Shkarina, Talanta, 2007, 71, 13.

22 A. Doménech-Carbó, R. Gavara, P. Hernández and I. Domínguez, Talanta, 2015, 144, 1207.

23 A. Doménech-Carbó, N. Montoya, P. Soriano and E. Estrelles, Curr. Opin. Plant Biol., 2018, 16, 9.

24 B. Marselli, J. Garcia-Gomez, P. A. Michaud, M. A. Rodrigo and C. Comninellis, J. Electrochem. Soc., 2003, 150, D79.

25 T. A. Enache, A. M. Chiorcea-Paquim, O. Fatibello-Filho and A. M. Oliveira-Brett, Electrochem. Commun., 2009, 11, 1342.

26 A. Kapałka, G. Foti and C. Comninellis, Electrochim. Acta, 2009, 54, 2018.

27 F. Scholz and B. Meyer, Voltammetry of solid microparticles immobilized on electrode surfaces in Electroanalytical
Chemistry, A Series of Advances, ed. A. J. Bard and I. Rubinstein, Marcel Dekker, New York 1998, 20, pp. 1-86.

28 F. Scholz, U. Schröder, R. Gulaboski, and A. DoménechCarbó, Electrochemistry of Immobilized Particles and Droplets. Springer International Publishing, BerlinHeidelberg, 2nd edn, 2015.

29 A. Doménech-Carbó, J. Labuda and F. Scholz, Pure Appl. Chem., 2013, 85, 609.

30 Š. Komorsky-Lovrić and I. Novak, Collect. Czech. Chem. Commun., 2009, 74, 1467.

31 Š. Komorsky-Lovrić and I. Novak, J. Food Sci., 2009, 76, C916. 32 A. Doménech-Carbó, A. M. Ibars, J. Prieto-Mossi, E. Estrelles, F. Scholz, G. Cebrián-Torrejón and M. Martini, New J. Chem., 2015, 39, 7421.

33 A. Doménech-Carbó, A. M. Ibars, J. Prieto-Mossi, E. Estrelles, M. T. Doménech-Carbó, A. S. Ortiz-Miranda and Y. Lee, Electroanalysis, 2017, 29, 643.

34 A. Doménech-Carbó, G. Cebrián-Torrejón, A. Lopes-Souto, M. Martins De Moraes, M. Jorge-Kato, J. Fechine-Tavares and J. M. Barbosa-Filho, RSC Adv., 2015, 5, 61006.

35 J.-J. Qin, Y. Huang, D. Wang, X.-R. Cheng, Q. Zeng, S.-D. Zhang, Z.-L. Hu, H.-Z. Jin and W.-D. Zhang, RSC Adv., 2012, 3, 1307.

36 L.-P. Chen, G.-Z. Wu, H.-Y. Dong, N. Yang, W.-D. Zhang and H.-L. Li, RSC Adv., 2016, 6, 103296.

37 X.-F. Zhang, J. Ren, X.-R. Cheng, H.-Z. Jin and W.-D. Zhang, RSC Adv., 2015, 5, 1979.

38 X.-R. Cheng, W.-H. Shao, S.-D. Zhang, G.-W. Wang, L. Shan, Y.-H. Shen, Q.-Y. Sun, H.-Z. Jin and W.-D. Zhang, RSC Adv., 2014, 4, 33815.

39 M. S. Gencic and N. S. Radulovic, RSC Adv., 2015, 5, 72670.

40 J. P. Carini, F. Klamt and V. Linck Bassani, RSC Adv., 2014, 4, 3131.

41 T. Grygar, S. Kucková, D. Hradil and D. Hradilová, J. Solid State Electrochem., 2003, 7, 706.

42 A. Doménech-Carbó, M. T. Doménech-Carbó and M. C. Saurí-Peris, Talanta, 2005, 66, 769.

43 J. Kim, R. L. Wilson, J. B. Case and B. M. Binder, Plant Physiol., 2012, 160, 1567.

44 Y. Laghmouchi, O. Belmehdi, A. Bouyahya, N. Skali Senhaji and J. Abrinia, Biocatal. Agric. Biotechnol., 2017, 10, 156.

45 A. A. Andergerg, B. G. Baldwin, R. G. Bayer, J. Breitwieser, C. Jeffrey, M. O. Dillon and P. O. Karis, Compositae, in Flowering Plants Eudicots, Springer, Berlin-Heidelberg, 2007, pp. 61-588.

46 P. Parolin, M. Ion-Scotta and C. G. Bresh, Int. J. Exp. Bot., 2016, 83, 251.

47 W. Greuter, Compositae (pro parte majore), in Compositae Euro+Med Plantbase - the informationr Resource for EuroMediterranean plant diversity, ed. W. Greuter and E. Von Raab-Straube, Publisher on the Internet http:// ww2.bgbm.org/EuroPlusMed/, 2006-2009, accessed February 27th 2019; V. De Laurentis, M. A. Losacco, M. A. Milillo and O. Lai, Delpinoa, 2002, 44, 115.

48 A. Nikolakaki and N. S. Christodoulakis, Bot. J. Linn. Soc., 2004, 144, 437. 
49 G. L. Miguel, C. Faleiro, L. Cavaleiro, L. Salgueiro and J. Casanova, Phytother. Res., 2008, 22, 259.

50 P. Karageorgou, E. Levizou and Y. Manetas, Flora, 2002, 197, 285.

51 I. Tomac and M. Šeruga, Int. J. Electrochem. Sci., 2016, 11, 2854.

52 J. Xu, W. Huang and R. L. McCreery, J. Electroanal. Chem., 1996, 410, 235.

53 F. Kuang, D. Zhang, Y. Li, Y. Wan and B. Hou, J. Solid State Electrochem., 2009, 13, 385.
54 K. Kano, T. Mabuchi, B. Uno, Y. Esaka, T. Tanaka and M. Iinuma, J. Chem. Soc., Chem. Commun., 1994, 5, 593.

55 V. Krishnamachari, L. H. Levine and P. W. Paré, J. Agric. Food Chem., 2002, 50, 4357.

56 I. Gülçin, Arch. Toxicol., 2012, 86, 345.

57 I. G. Zenkevich, A. Y. Eshchenko, S. V. Makarova, A. G. Vitenberg, Y. G. Dobryakov and V. A. Utsal, Molecules, 2007, 12, 654 . 